\title{
New Directions in Transition Metal Catalyzed Carbonylation Chemistry
}

\author{
Dennis U. Nielsen, Karoline T. Neumann, and Troels Skrydstrup*
}

\begin{abstract}
Carbon monoxide (CO) represents an important C1-building block for the construction of some of the most fundamental chemical functionalities carrying a carbon-oxygen double bond. Transition metal catalysis plays a key role in promoting such transformations. We have earlier shown that the combination of palladium catalysis with $\mathrm{CO}$ releasing molecules and the two-chamber reactor, COware, provides a convenient and safe means for performing traditional Pd-catalyzed carbonylative couplings, as well as being a platform for the discovery of new carbonylation reactions. Furthermore, the method can be adapted to ${ }^{13} \mathrm{C}$ - and ${ }^{14} \mathrm{C}$-isotope labeling, as well as providing for a suitable setting for developing efficient carbonylation reactions with ${ }^{11} \mathrm{CO}$. Herein, we provide a short overview of our latest findings in this area with emphasis on carbonylative couplings with fluorinated building blocks, but also discuss our efforts to develop viable Ni-catalyzed carbonylations with aliphatic substrates, which can be performed efficiently under low CO partial pressures.
\end{abstract}

Keywords: Carbonylation · Catalysis · Fluorination · Isotope labeling · Nickel · Palladium

Dr. Dennis $U$. Nielsen and Dr. Karoline

T. Neumann both obtained their PhD degrees under the supervision of Prof. Troels Skrydstrup and are currently working as post docs in the Skrydstrup lab. Troels Skrydstrup is currently full professor at the Interdisciplinary Nanoscience Center and the Department of Chemistry at Aarhus University. He leads a center in carbon dioxide activation (CADIAC) funded by the Danish National Research Foundation. He has a keen interest in the use of single electron reducing reagents and transition metal catalysis in organic synthesis, and recent efforts over the last few years have been focused on the development of synthetic techniques for the safe handling of gaseous reagents in catalytic protocols. He has over 250 publications and is co-founder and coowner of the spin-off company, SyTracks. Troels Skrydstrup was elected as a fellow of the Royal Danish Academy of Sciences and Letters in 2008, and in 2012, he was knighted by the Danish Queen. He is the recent recipient of the Melvin Calvin Award 2018 from the International Isotope Society.

\section{Introduction}

Palladium-catalyzed carbonylation reactions have proven to be a robust and versatile method for installing carbonyl groups into a variety of compounds since the initial reports from Heck and co-workers. ${ }^{[1]} \mathrm{Al}-$ though $\mathrm{CO}$ is an excellent one-carbon building block, it is not without its drawbacks as the handling of the toxic gas is often a cause for concern. Many research groups have therefore explored the potential of employing CO-releasing molecules (CORMs) in order to eliminate the risks of exposure to CO. ${ }^{[2]}$ In 2011, we reported on two different CORMs that could produce $\mathrm{CO}$ ex situ in a two-chamber system enabling a safe and efficient alternative for performing traditional CO-consuming reactions. ${ }^{[3]}$ The application of this methodology in traditional Pd-catalyzed carbonylative transformations, such as amino- and alkoxycarbonylations and carbonylative analogs of named cross-coupling reactions (Suzuki-Miyaura and Sonogashira) was summarized in an account from $2016 .{ }^{[4]}$ In this work, we wish to report on some recent discoveries developed in our laboratories. Focus will be directed towards Pd-catalyzed carbonylative transformations using fluorinated building blocks, and efforts on exploiting nickel as an effective catalyst for carbonylation chemistry.

\section{Carbonylative Reactions using Fluorinated Reagents}

Incorporation of fluorine atoms into bioactive compounds often leads to increased lipophilicity and metabolic stability. Fluorinated drugs have become more common, ${ }^{[5]}$ and a recent table from the Njardarson group, ${ }^{[6]}$ summarizing the top pharmaceutical products by retail sales in 2016, reveals that 12 out of the top 30 low molecular weight pharmaceutical drugs contained a fluorinated compound, some of which are depicted in Fig. 1. As can be seen in this Figure, different fluorination patterns (mono-, di- and trifluorination) and positioning $\left(\mathrm{C}\left(\mathrm{sp}^{2}\right)-\mathrm{F}\right.$ and $\left.\mathrm{C}\left(\mathrm{sp}^{3}\right)-\mathrm{F}\right)$ are utilized. Therefore, new and efficient methodologies for installing fluorine atoms into bioactive compounds are highly desirable. We have previously developed a carbonylative methodology transforming perfluorinated arenes into the corresponding diarylketone through $\mathrm{C}-\mathrm{H}$ activation. ${ }^{[7]}$ In order to access more diverse fluorinated scaffolds, $\alpha, \alpha, \alpha$-bromodifluoro-carbonyl compounds were selected as possible coupling partners. Hartwig, Zhang and others have previously demonstrated the potential of using these fluorinated molecules in a range of $\alpha$-arylation procedures. ${ }^{[8,9]}$ Given our prior experience with carbonylative $\alpha$-arylation reactions for accessing 1,3-dicarbonyl structures, ${ }^{[10]}$ these fluorinated molecules were chosen as the electrophile for forming $\alpha, \alpha$-difluoro analogs of these useful scaffolds. The optimized conditions and some representative examples are depicted in Scheme 1. ${ }^{[1,12]}$ Starting from different aryl boronic acid derivatives (Ar-Bpin, Ar-Bnep, Ar-BF $\mathrm{K}$ ), high yields could be obtained for the $\beta$-ketoamides such as $\mathbf{1}$ and $\mathbf{2}$ and the corresponding $\beta$-ketoester as for $\mathbf{3}$. This latter compound could be transformed to the corresponding $\alpha, \alpha$-difluorinated acetophenone $\mathbf{4}$ through an acid-mediated decarboxylation, or to pyrazalone $\mathbf{5}$ via a condensation-acyl 
substitution sequence. The $\beta$-ketoamide 6 was isolated using ${ }^{13} \mathrm{CO}$ generated from ${ }^{13} \mathrm{COgen}$ in a good yield (75\%), and could further be isotopically-enriched by reduction using $\mathrm{NaBD}_{4}$ to the $[\mathrm{M}+4]$-diol 7.

The developed methodology illustrated in Scheme 1 was limited to aryl boronic derivatives. The concept could nonetheless be extended to include aliphatic boron reagents ${ }^{[13]}$ by lowering the temperature and increasing the $\mathrm{CO}$ pressure as shown in Scheme 2. ${ }^{[14]}$ The nucleophilic boron reagents were obtained from the hydroboration of the corresponding alkene in the presence of $(9-\mathrm{BBN})_{2}$. Octyl-substituted $\alpha, \alpha$-difluoro- $\beta$-ketoamides $\mathbf{8}$ and $\mathbf{9}$ could be isolated in good yields and ${ }^{13} \mathrm{C}$-labeling was also possible using ${ }^{13} \mathrm{COgen}$ as for compound 10. Hydroborated styrenes could also be utilized as nucleophiles for this carbonylative cross-coupling as exemplified by $\beta$-ketoamides $\mathbf{1 1}$ and $\mathbf{1 2}$. Notably, the $\mathrm{C}\left(\mathrm{sp}^{2}\right)-\mathrm{Br}$ bond in $\mathbf{1 1}$ remained untouched under these mild conditions allowing for potential further manipulations. Furthermore, three additional fluorine atoms could be incorporated into the desired product $\mathbf{1 2}$ by having a $\mathrm{CF}_{3}$-group pre-installed on the electrophile. Finally, a mono-fluorinated $\beta$-ketoester 13 could be generated in a good yield by employing ethyl 2-bromo-2-fluoroacetate as the electrophile.

Besides $\alpha, \alpha, \alpha$-bromodifluoroamides and esters described above, perfluorinated alkyl iodides have also been examined as electrophiles in transition-metal catalyzed reactions. Nevado and Chajadaj reported on the exploitation of such compounds in three-component $\mathrm{Pd}$-catalyzed reaction with boronic acids and alkynes to access tri- and tetra-substituted perfluorinated olefins. ${ }^{[15]}$ Furthermore, a four-component methodology based on these reports incorporating $\mathrm{CO}$ as the fourth reactant for making $\alpha, \beta$-unsaturated esters and amides was recently reported by Liang and co-workers.[16] Inspired by these results, we recently developed a Pd-catalyzed four component methodology for accessing perfluorinated enones and indolin2-ones. ${ }^{[17,18]}$ Representative examples are illustrated in Scheme 3.

Using perfluorinated iodobutane as the electrophile combined with (hetero)aro-

Fig. 1. Top-selling fluorinated pharma-

ceuticals.

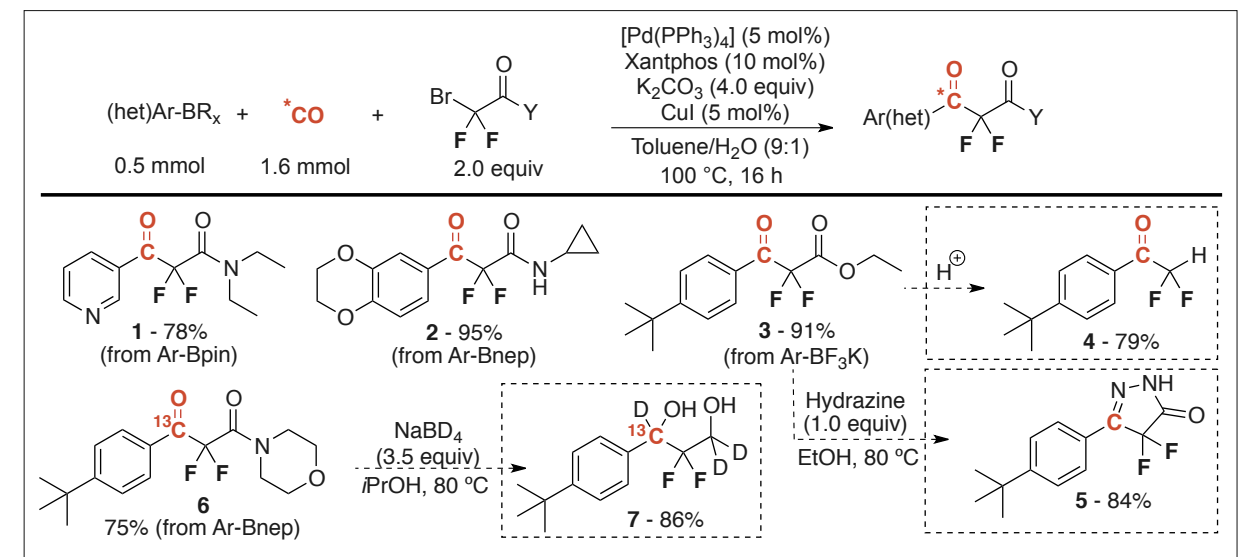

Scheme 1. Access to $\beta$-aryl- $\alpha, \alpha$-difluoro- $\beta$-ketoamides and -esters using aryl boronic acid derivatives.

matic boronic acids and phenylacetylene or pentyne allowed for the isolation of enones 14-16 in good yields. Alkyl iodides containing longer perfluorinated chains could also be utilized as exemplified by compounds $\mathbf{1 7}$ and 18. Furthermore, applying ethyl $\alpha, \alpha, \alpha$-bromodifluoroacetate, similar to the work shown in Schemes 1 and 2, generated the desired 1,5-ketoester 19 in a reasonable yield (55\%). Interestingly, when 2-ethynylanilines were investigated in the presence of a catalytic amount of boronic acid (for catalyst activation), the formation of the indolin-2-ones could be achieved as exemplified with the products $\mathbf{2 0}$ and $\mathbf{2 1}$.

The developed methodologies presented vide supra all relied on fluorinated electrophiles. The most popular fluorinated nucleophile is arguably the Ruppert-Prakash reagent $\left(\mathrm{TMSCF}_{3}\right)$, which has been widely used for introducing a $\mathrm{CF}_{3}$ group into a

\section{$\left[\mathrm{Pd}\left(\mathrm{PPh}_{3}\right)_{4}\right](5 \mathrm{~mol} \%)$}

Xantphos (10 mol\%)

$\mathrm{K}_{2} \mathrm{CO}_{3}$ (4.0 equiv)

Cul (5 mol\%)

Toluene/ $\mathrm{H}_{2} \mathrm{O}(10: 1)$

$50{ }^{\circ} \mathrm{C}, 24 \mathrm{~h}$

$$
\text { Alkyl }{ }^{* 11}{ }_{F}^{O}{ }_{F}^{O}
$$

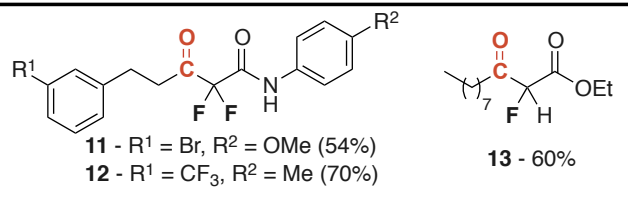

Scheme 2. Formation of fluorinated-1,3-dicarbonyl compounds using alkyl-9-BBN substrates. plethora of organic compounds. ${ }^{[19]}$ Given our interest in carbonylation and fluorination chemistry we sought to utilize this useful reagent in a carbonylative transformation. Notably, there are no examples of using $\mathrm{TMSCF}_{3}$ in carbonylation chemistry in the literature. This can most likely be ascribed to the instability of the trifluoromethyl anion formed in situ. A solution to this challenge is to form copper-ligated $\mathrm{CF}_{3}$ complexes, which have been studied by the groups of Hartwig and Grushin. ${ }^{[20]} \mathrm{Wu}$ and co-workers have recently published a carbonylative transformation of aryl iodides using stoichiometric ' $\mathrm{CuCF}_{3}$ ' for accessing trifluoromethyl ketones. ${ }^{[21]}$ Similar to this, the Grushin group have studied the formation of fluorinated ketones from acid chlorides and stoichiometric ' $\mathrm{CuCF}_{2} \mathrm{CF}_{3}$ '. ${ }^{[22]}$ Since the free $\mathrm{CF}_{3}$ anion is not present in the above-mentioned strategies, addition to the electrophilic fluorinated ketone forming the corresponding hexafluoroisopropanol (HFIP) or decafluoroisopropanol derivatives was avoided. Nevertheless, a carbonylative approach relying on the double addition of $\mathrm{TMSCF}_{3}$ for accessing the HFIP motif would be interesting as compounds containing this motif display interesting inhibitory activity for the enzyme malonyl-CoA decarboxylase. ${ }^{[23]}$ This goal was realized by applying a Pd-catalyzed carbonylative transformation of aryl bromides to the corresponding acid fluorides, developed by Manabe,[24] 


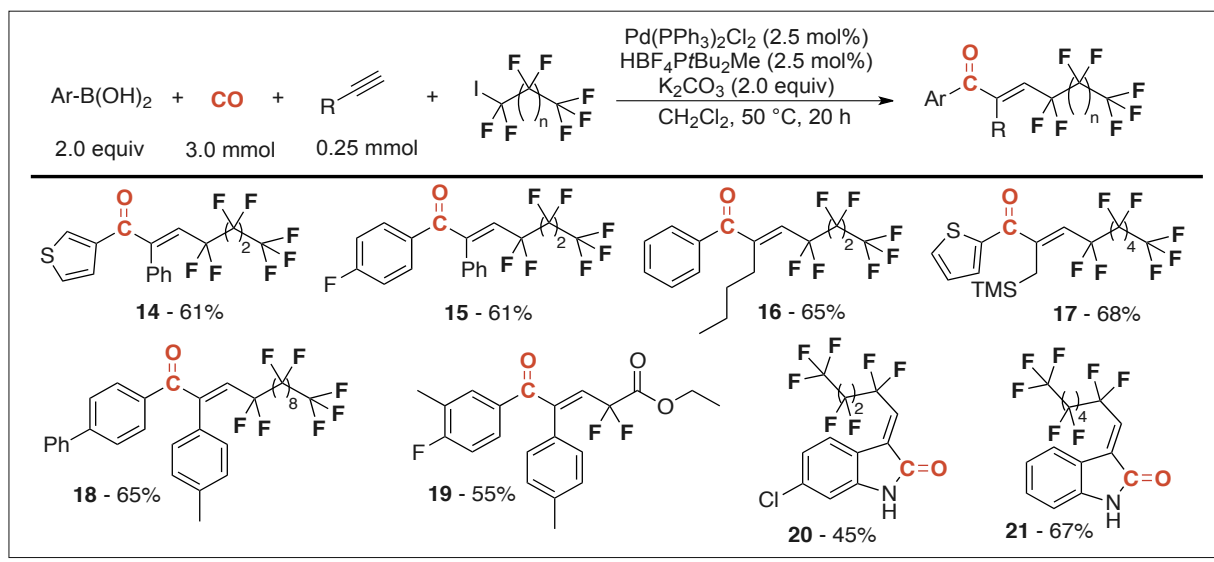

Scheme 3. Four-component reactions affording perfluorinated enones and indolin-2-ones.

followed by addition of two equivalents $\mathrm{TMSCF}_{3}$ as shown in Scheme 4.[25]

5-Bromopyrimidine or 3,5-dibromopyridine could effectively be transformed to incorporate one or two HFIP groups, respectively, as shown with compounds 22 and 23. Fluorosulfates have recently emerged as reactive coupling partners for cross-couplings or SuFEx click chemistry as introduced by Sharpless. [26] Veryser et al recently developed an efficient protocol for converting phenols into fluorosulfates. ${ }^{[27]}$ This method could be utilized to convert estrone into the corresponding fluorosulfate, which was a suitable electrophile for the HFIP-transformation as demonstrated for the product 24. Furthermore, instead of employing $\mathrm{COgen}$ as the $\mathrm{CO}$ source, $\mathrm{CO}_{2}$ could be exploited in the presence of a disilane and catalytic $\mathrm{CsF}$ providing a similar yield of the hexafluoride-containing compound $24(68 \%) \cdot{ }^{[28]}{ }^{13} \mathrm{C}$-labeling of estrone proved possible by employing ${ }^{13} \mathrm{COgen}(\mathbf{2 5})$. The these conditions, however, having more activated ketone groups present in the starting material allowed for the incorporation of an additional $\mathrm{CF}_{3}$ group as exemplified with compound 26. Finally, two bioactive molecules could be isolated in high yields including their ${ }^{13} \mathrm{C}$-isotopically labeled versions (compounds 27-30).

\section{Nickel-catalyzed Carbonyative Reactions} ketone group remained untouched under

The carbonylative transformation presented vide supra all relied on ligated palladium complexes as the active catalyst. Considering the availability and cost of palladium, the development of similar carbonylations relying on catalysts prepared from less expensive Earth-abundant metals would be noticeably more desirable. In this respect, nickel is interesting being a first-row transition metal in the same main group as palladium. However, until recently, only sporadic examples on the use of $\mathrm{Ni}$ catalyzed carbonylative reactions have been reported in the literature, ${ }^{[29]}$ which is most likely due to the preference of $\mathrm{Ni}(0)$ to form stable carbonyl clusters in the presence of $\mathrm{CO}$ (e.g. $\left.\mathrm{Ni}(\mathrm{CO})_{4}\right)$. Therefore, solutions such as slow CO-release from formates or omission of stirring have been presented by Ogoshi. ${ }^{[30]}$ In an attempt to develop a more general Ni-catalyzed system suitable for handling a CO-atmosphere, we recently decided to investigate nickel-pincer complexes. These tri-coordinated ligands have been demonstrated to chelate a range of metals, and thus should be good candidates for avoiding deactivation of the nickel catalyst into carbonyl clusters. Screening different pincer ligands based on a pyrrole-[31,32] or

1) $\mathrm{Pd}(\mathrm{OAc})_{2}(3.0 \mathrm{~mol} \%)$
Xantphos $(4.5 \mathrm{~mol} \%)$
$\mathrm{KF}(3.5$ equiv)
$\mathrm{DMF}, 80^{\circ} \mathrm{C}, 16 \mathrm{~h}$
$2 \mathrm{TMSCF}_{3}(2.2$ equiv)
$20^{\circ} \mathrm{C}, 1 \mathrm{~h}$

$\mathrm{X}=\mathrm{Br}$ or $\mathrm{OSO}_{2}$

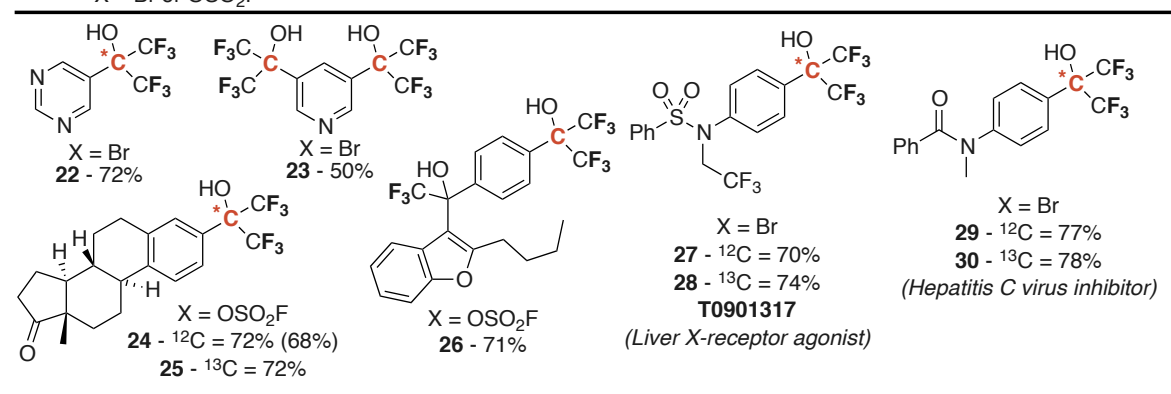

Scheme 4. Pd-catalyzed carbonylative approach towards hexafluoroisopropanol-containing arenes. diarylaniline ${ }^{[33]}$ scaffold did not provide any positive results for the carbonylative Negishi cross-coupling chosen as the test reaction. Nevertheless, an effective catalyst was produced from the combination of $\mathrm{NiCl}_{2}$ and the 8-aminoquinoline-based pincer ligand reported by Punji and co-workers ${ }^{[34]}$ for the carbonylative coupling of benzyl bromides with alkyl organozinc reagents as demonstrated in Scheme 5.[35] Pentafluorinated benzyl bromide proved to be an effective coupling partner providing ketone 31, and otherwise reactive electrophiles for transition metal cross couplings such as aryl tosylate, aryl bromide or even aryl iodide were well-tolerated under the optimized conditions providing the desired carbonylative coupling product 32-34. Benzylic heterocycles such as a pyridine, pyrazole or benzothiophene could be activated as electrophiles providing ketones 35-37, resp., with the latter being formed as its carbon-13 labeled version when ${ }^{13} \mathrm{COgen}$ was applied. Ketones 31-37 were all prepared using a propyl organozinc reagent, however, other aliphatic Negishi reagents carrying a masked aldehyde, an ethyl carboxylate, an olefin or a cyclopentyl ring could all form the corresponding ketones 38-41 in high yields from 1-(bromomethyl)-4-(tert-butyl) benzene. The mechanism for the transformation is proposed to go through a catalytic cycle involving a bimetallic oxidative addition sequence as earlier demonstrated by $\mathrm{Hu}$ in his work on the use of $\mathrm{Ni}(\mathrm{II})$-pincer complexes for the highly effective coupling of alkyl Grignard reagents with alkyl halides.[36,37]

\section{Conclusion}

In this short account, we have presented some of our most recent findings in the pursuit of novel carbonylative transformations. Aromatic and aliphatic organoboron reagents could be coupled to $\alpha, \alpha, \alpha$ bromodifluorinated carbonyls forming a range of $\alpha, \alpha$-difluorinated $\beta$-ketoamides and esters. Furthermore, perfluorinated alkyl iodides could effectively be combined with $\mathrm{CO}$, aryl boronic acids and alkynes in a four-component reaction providing access to perfluorinated enones and indolin2-ones. Additionally, the Ruppert-Prakash reagent was demonstrated to participate in a carbonylative transformation forming aryl hexafluoroisopropanol derivatives in good yields from aryl bromides and fluorosulfates. Finally, a rare example of a Nicatalyzed carbonylative cross-coupling for the construction of $\mathrm{C}\left(\mathrm{sp}^{3}\right)-\mathrm{C}\left(\mathrm{sp}^{3}\right)$ ketones was demonstrated enabled by a new pincer ligand. Future work will focus on expanding both the methodologies and in particular for obtaining a better understanding of the operating mechanisms. 


\section{Acknowledgements}

We are deeply appreciative of generous financial support from the Danish National Research Foundation (grant no. DNRF118), the Lundbeck Foundation, and Aarhus University.

\section{Conflicts of Interest}

Troels Skrydstrup is co-owner of SyTracks a/s, which commercializes the two-chamber technology and COgen.

Received: June 14, 2018

[1] a) A. Schoenberg, I. Bartoletti, R. F. Heck, J. Org. Chem. 1974, 39, 3318; b) A. Schoenberg, R. F. Heck, J. Org. Chem. 1974, 39, 3327; c) A Schoenberg, R. F. Heck, J. Am. Chem. Soc. 1974 96,$7761 ;$ d) A. Brennführer, H. Neumann, M. Beller, Angew. Chem. Int. Ed. 2009, 48, 4114 e) X.-F. Wu, H. Neumann, M. Beller, Chem Soc. Rev. 2011, 40, 4986; f) C. F. J. Barnard, Organometallics 2008, 27, 5402; g) S. T. Gadge, B. M. Bhanage, $R S C A d v$. 2014, 4, 10367.

[2] a) L. Wu, Q. Liu, R. Jackstell, M. Beller, Angew. Chem. Int. Ed. 2014, 53, 6310; b) P. Gautam, B M. Bhanage, Catal. Sci. Technol. 2015, 5, 4663 c) T. Morimoto, K. Kakiuchi, Angew. Chem. Int Ed. 2004, 43, 5580 .

[3] a) P. Hermange, A. T. Lindhardt, R. H. Taaning, K. Bjerglund, D. Lupp, T. Skrydstrup, J. Am Chem. Soc. 2011, 133, 6061; b) S. D. Friis, R H. Taaning, A. T. Lindhardt, T. Skrydstrup, $J$. Am. Chem. Soc. 2011, 133, 18114.

[4] S. D. Friis, A. T. Lindhardt, T. Skrydstrup, Acc. Chem. Res. 2016, 49, 594

[5] a) S. Purser, P. R. Moore, S. Swallow, V. Gouverneur, Chem. Soc. Rev. 2008, 37, 320; b) J. Wang, M. Sanchez-Rosello, J. L. Acena, C. del Pozo, A. E. Sorochinsky, S. Fustero, V. A. Soloshonok, H. Liu, Chem. Rev. 2014 114,2432 ; c) K. Müller, C. Faeh, F. Diederich, Science, 2007, 317, 1881; d) Y. Zhou, J. Wang, Z. Gu, S. Wang, W. Zhu, J. L. Acena, V. A. Soloshonok, K. Izawa, H. Liu, Chem. Rev 2016, 116, 422.

[6] http://njardarson.lab.arizona.edu/sites/njardarson.lab.arizona.edu/files/2016Top200Pharmac euticalRetailSalesPosterLow Res V3 0.pdf

[7] Z. Lian, S. D. Friis, T. Skrydstrup, Chem Commun. 2015, 51, 1870.

[8] For examples on the use of $\alpha, \alpha$-difluoro carbonyls using transition-metal catalysis see: a) $\mathrm{S}$ I. Arlow, J. F. Hartwig, Angew. Chem. Int. Ed. 2016, 55, 4567; b) K. Fujikawa, Y. Fujioka, A. Kobayashi, H. Amii, Org. Lett. 2011, 13, 5560 c) C. Guo, R.-W. Wang, F.-L. Qing, J. Fluorine Chem. 2012, 143, 135; d) Z. Feng, Q. Q. Min, Y. L. Xiao, B. Zhang, X. Zhang, Angew. Chem. Int. Ed. 2014, 53, 1669; e) A. Tarui, S. Shinohara, K. Sato, M. Omote, A. Ando, Org. Lett. 2016, 18, 1128; f) S. Ge, W. Chaladaj, J. F. Hartwig, J. Am. Chem. Soc. 2014, 136, 4149; g) S. Ge, S I. Arlow, M. G. Mormino, J. F. Hartwig, J. Am Chem. Soc. 2014, 136, 14401.

[9] a) B. C. Hamann, J. F. Hartwig, J. Am. Chem Soc. 1997, 119, 12382; b) M. Palucki, S. L. Buchwald, J. Am. Chem. Soc. 1997, 119 11108 ; c) T. Satoh, Y. Kawamura, M. Miura, M Nomura, Angew. Chem. Int. Ed. 1997, 36, 1740 d) F. Bellina, R. Rossi, Chem. Rev. 2010, 110 , 1082.

[10] For examples on the Pd-catalyzed carbonylative $\alpha$-arylation see: a) T. M. Gøgsig, R. H. Taaning, A. T. Lindhardt, T. Skrydstrup, Angew. Chem. Int. Ed. 2011, 51, 798; b) D. U. Nielsen, C. Lescot, T. M. Gøgsig, A. T. Lindhardt, T. Skrydstrup, Chem. Eur. J. 2013, 19, 17926; c) S. Korsager, D. U. Nielsen, R. H. Taaning, T. Skrydstrup, Angew. Chem. Int. Ed. 2013, 52,

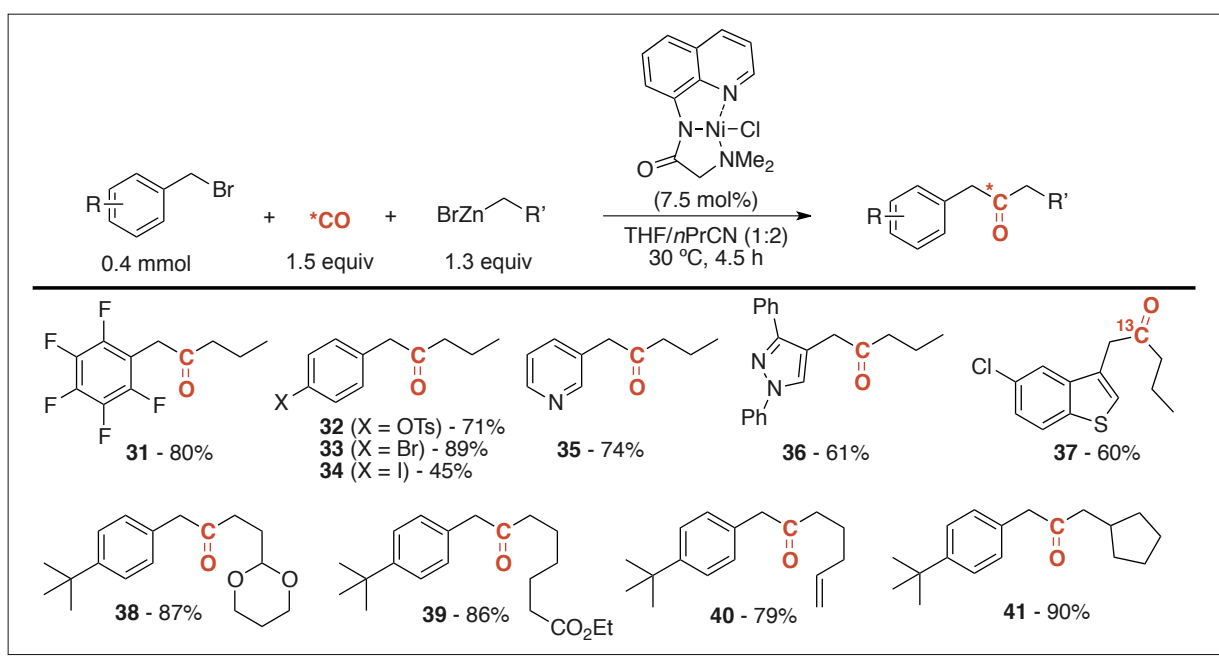

Scheme 5. Ni-catalyzed carbonylative Negishi cross-coupling for the synthesis of benzyl alkyl ketones.

9763; d) S. Korsager, D. U. Nielsen, R. H. Taaning, A. T. Lindhardt, T. Skrydstrup, Chem. Eur. J. 2013, 19, 17687; e) D. U. Nielsen, S. Korsager, A. T. Lindhardt, T. Skrydstrup, $A d v$. Synth. Catal. 2014, 356, 3519; f) M. T. Jensen, M. Juhl, D. U. Nielsen, M. F. Jacobsen, A. T. Lindhardt, T. Skrydstrup, J. Org. Chem. 2016, 81,1358 .

[11] T. L. Andersen, M. W. Frederiksen, K. Domino, T. Skrydstrup, Angew. Chem. Int. Ed. 2016, 55, 10396.

[12] Zhang and co-workers published a similar paper independently: H.-Y. Zhao, Z. Feng, Z. Luo, X. Zhang, Angew. Chem. Int. Ed. 2016, 55, 10401.

[13] For examples using aliphatic organoboron reagents see: a) S. R. Chemler, D. Trauner, S. D. Danishefsky, Angew. Chem. Int. Ed. 2001, 40, 4544; b) B. Saito, G. C. Fu, J. Am. Chem. Soc. 2007, 129, 9602; c) H. Doucet, Eur. J. Org. Chem. 2008, 2013; d) N. Miyaura, T. Ishiyama, M. Ishikawa, A. Suzuki, Tetrahedron Lett. 1986, 27, 6369; e) T. Ishiyama, N. Miyaura, A. Suzuki, Tetrahedron Lett. 1991, 32, 6932.

[14] H. Yin, J. J. Kumke, K. Domino, T. Skrydstrup, ACS Catal. 2018, 8, 3853

[15] a) Z. Li, A. Garcia-Dominguez, C. Nevado, J. Am. Chem. Soc. 2015, 137, 11610; b) S. Domanski, W. Chaladaj, ACS Catal, 2016, 6, 3452 .

[16] Q. Wang, Y. T. He, J. H. Zhao, Y. F. Qiu, L. Zheng, J. Y. Hu, Y. C. Yang, X. Y. Liu, Y. M. Liang, Org. Lett. 2016, 18, 2664.

[17] H. Yin, T. Skrydstrup, J. Org. Chem. 2017, 82, 6474.

[18] The groups of Chaladaj and Liang published similar protocols at the same time: a) S. Domanski, O. Staszewska-Krajewska, W. Chaladaj, J. Org. Chem. 2017, 82, 7998; b) Q. Wang, L. Zheng, Y.-T. He, Y.-M. Liang, Chem. Commun. 2017, 53, 2814

[19] a) I. Ruppert, K. Schlich, W. Volbach, Tetrahedron Lett 1984, 25, 2196; b) G. K. S. Prakash, A. K. Yudin, Chem. Rev. 1997, 97, 757; c) G. K. S. Prakash, M. Mandal, J. Fluorine Chem. 2001, 112, 123; d) G. K. S. Prakash, P. V. Jog, P. T. D. Batamack, G. A. Olah, Science 2012, 338, 1324; e) X. Liu, C. Xu, M. Wang, Q. Liu, Chem. Rev. 2015, 115, 683 .

[20] a) H. Morimoto, T. Tsubogo, N. D. Litvinas, J. F. Hartwig, Angew. Chem. Int. Ed. 2011, 50 , 3793; b) O. A. Tomashenko, E. C. EscuderoAdán, M. M. Belmonte, V. V. Grushin, Angew. Chem. Int. Ed. 2011, 50, 7655.

[21] F. Zhu, G. Yang, S. Zhou, X.-F. Wu, RSC Adv. 2016, 6, 57070

[22] I. Panferova, F. M. Miloserdov, A Lischchynskyi, M. M. Belmonte, J. Benet-
Buchholz, V. V. Grushin, Angew. Chem. Int. Ed. 2015, 54, 5218.

[23] J.-F. Cheng, C. C. Mak, Y. Huang, R. Penuliar M. Nishimoto, L. Zhang, M. Chen, D. Wallace, T. Arrhenius, D. Chu, G. Yang, M. Barbosa, R. Barr, J. R. B. Dyck, G. D. Lopaschuk, A. M. Nadzan, Bioorg. Med. Chem. Lett. 2006, 16 , 3484.

[24] T. Ueda, H. Konishi, K. Manabe, Org. Lett 2013, 15, 5360 .

[25] K. Domino, C. Veryser, B. A. Wahlqvist, C. Gaardbo, K. T. Neumann, K. Daasbjerg, W. M. De Borggraeve, T. Skrydstrup, Angew. Chem. Int. Ed. 2018, 57, 6858

[26] a) J. Dong, L. Krasnova, M. G. Finn, K. B. Sharpless, Angew. Chem. Int. Ed. 2014, 53, 9430; b) J. Dong, K. B. Sharpless, L. Kwisnek, J. S. Oakdale, V. V. Foking, Angew. Chem. Int. Ed. 2014, 53, 9466; c) B. Goa, L. Zhang, Q. Zheng, F. Zhou, L. M. Klivansky, J. Lu, Y. Liu, J. Dong, P. Wu, K. B. Sharpless, Nat. Chem. 2017, 9, 1083

[27] C. Veryser, J. Demaerel, V. Bieliunas, P. Gilles, W. M. De Borggraeve, Org. Lett. 2017, 19, 5244.

[28] a) C. Lescot, D. U. Nielsen, I. S. Makarov, A. T. Lindhardt, K. Daasbjerg, T. Skrydstrup, J. Am. Chem. Soc. 2014, 136, 6142; b) Z. Lian, D. U. Nielsen, K. Daasbjerg, T. Skrydstrup, Nat. Commun. 2016, 7, 13782; c) M. Flinker, S. Lopez, D. U. Nielsen, K. Daasbjerg, F. Jensen, T. Skrydstrup, Synlett 2017, 28, 2439.

[29] J.-B. Peng, F.-P. Wu, X.-F. Wu, Chem. Rev 2018, doi: $10.1021 /$ acs chemrev. 8 b00068

[30] a) Y. Hoshimoto, T. Ohata, Y. Sasaoka, M Ohashi, S. Ogoshi, J. Am. Chem. Soc. 2014, 136 , 15877; b) Y. Hoshimoto, K. Ashida, Y. Sasaoka, R. Kumar, K. Kamikawa, X. Verdaguer, A. Riera, M. Ohashi, S. Ogoshi, Angew. Chem. Int. Ed. 2017, 56, 8206.

[31] N. Grüger, H. Wadepohl, L. H. Gade, Dalton Trans. 2012, 41, 14028.

[32] G. T. Venkanna, S. Tammineni, H. D. Arman, Z J. Tonzetic, Organometallics 2013, 32, 4656.

[33] X. L. Hu, Chimia 2012, 66, 154, and references therein.

[34] V. Soni, R. A. Jagtap, R. G. Gonnade, B. Punji, ACS Catal. 2016, 6, 5666.

[35] T. L. Andersen, A. S. Donslund, K. T. Neumann, T. Skrydstrup, Angew. Chem. Int. Ed. 2018, 57, 800

[36] J. Breitenfeld, J. Ruiz, M. D. Wodrich, X. L. Hu, J. Am. Chem. Soc. 2013, 135, 12004.

[37] J. Breitenfeld, M. D. Wodrich, X. L. Hu, Organometallics 2014, 33, 5708 . 